\title{
Article \\ Polycyclic Aromatic Hydrocarbons Detected in Processed Meats Cause Genetic Changes in Colorectal Cancers
}

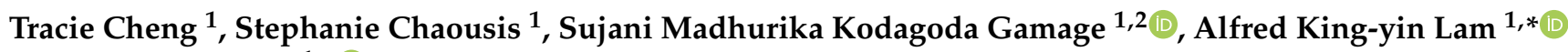 \\ and Vinod Gopalan 1,*iD \\ 1 Cancer Molecular Pathology, School of Medicine \& Dentistry, Griffith University, Gold Coast 4222, Australia; \\ tracie.cheng@griffith.edu.au (T.C.); schaousis@gmail.com (S.C.); \\ s.kodagodagamage@griffith.edu.au (S.M.K.G.) \\ 2 Department of Anatomy, Faculty of Medicine, University of Peradeniya, Kandy 20404, Sri Lanka \\ * Correspondence: a.lam@griffith.edu.au (A.K.-y.L.); v.gopalan@griffith.edu.au (V.G.); \\ Tel.: +61-756-780-718 (A.K.-y.L.); +61-756-780-717 (V.G.)
}

Citation: Cheng, T.; Chaousis, S.; Kodagoda Gamage, S.M.; Lam, A.K.-y.; Gopalan, V. Polycyclic Aromatic Hydrocarbons Detected in Processed Meats Cause Genetic Changes in Colorectal Cancers. Int. J. Mol. Sci. 2021, 22, 10959. https:/ / doi.org/10.3390/ijms222010959

Academic Editor: Hidekazu Suzuki

Received: 10 September 2021

Accepted: 6 October 2021

Published: 11 October 2021

Publisher's Note: MDPI stays neutral with regard to jurisdictional claims in published maps and institutional affiliations.

Copyright: (C) 2021 by the authors. Licensee MDPI, Basel, Switzerland. This article is an open access article distributed under the terms and conditions of the Creative Commons Attribution (CC BY) license (https:/ / creativecommons.org/licenses/by/ $4.0 /)$.

\begin{abstract}
Polycyclic aromatic hydrocarbons (PAHs) are commonly ingested via meat and are produced from high-temperature cooking of meat. Some of these PAHs have potential roles in carcinogenesis of colorectal cancer (CRC). We aimed to investigate PAH concentrations in eight types of commonly consumed ready-to-eat meat samples and their potential effects on gene expressions related to CRC. Extraction and clean-up of meat samples were performed using QuEChERS method, and PAHs were detected using GC-MS. Nine different PAHs were found in meat samples. Interestingly, roast turkey contained the highest total PAH content, followed by salami meat. Hams of varying levels of smokedness showed a proportional increase of phenanthrene (PHEN), anthracene (ANTH), and fluorene (FLU). Triple-smoked ham samples showed significantly higher levels of these PAHs compared to single-smoked ham. These three PAHs plus benzo[a]pyrene (B[a]P), being detected in three meat samples, were chosen as treatments to investigate in vitro gene expression changes in human colon cells. After PAH treatment, total RNA was extracted and rtPCR was performed, investigating gene expression related to CRC. B[a]P decreased mRNA expression of TP53. In addition, at high concentrations, $\mathrm{B}[\mathrm{a}] \mathrm{P}$ significantly increased KRAS expression. Treatments with $1 \mu \mathrm{M}$ PHEN, $25 \mu \mathrm{M}$, and $10 \mu \mathrm{M}$ FLU significantly increased KRAS mRNA expression in vitro, implying the potential basis for PAH-induced colorectal carcinogenesis. Opposingly, the ANTH treatment led to increased TP53 and APC expression and decreased KRAS expression, suggesting an anti-carcinogenic effect. To conclude, PAHs are common in ready-to-eat meat samples and are capable of significantly modifying the expression of key genes related to CRC.
\end{abstract}

Keywords: polycyclic aromatic hydrocarbons; colorectal cancer; processed meat; cancer genes

\section{Introduction}

Incidence of colorectal carcinoma (CRC) continues to increase, particularly in countries adopting a Western lifestyle [1]. As CRC is a disease of age and lifestyle, risk factors include diets high in meats and fats and low in fibre and vegetables, higher body-mass indices (BMI), and cigarette smoking [2,3]. Though many studies have been conducted in attempts to understand the mechanistic relationship between meat intake and CRC, there has not been a clear component of meat linked to CRC [4]. The International Agency for Research on Cancer (IARC) pronounced red and processed meat to be Group 1 carcinogens and suggested that polycyclic aromatic hydrocarbons are causative compounds to CRC [5].

Polycyclic aromatic hydrocarbons (PAHs) describe a group of organic compounds containing two or more aromatic rings [6]. They can contaminate meat through direct pyrolysis of food nutrients and from its deposition via smoke produced from incomplete combustion of organic matter [4]; thus, meats that have been smoked or barbequed often have high concentrations of PAHs [7]. Although PAHs are present ubiquitously throughout the 
environment, the main source of exposure is through the diet [8]. Whilst self-preparation of foods and meats can help to minimise PAH formation [7], processed meats still compose approximately $20 \%$ of meat intake of the Australian diet [9]. Once ingested, PAHs are metabolised to form carcinogenic metabolites [10].

Thirteen PAHs investigated in the current study were examined by the IARC and their carcinogenic classifications are detailed in Table 1 [11]. Due to its classification as a group 1 carcinogen, a lot of research has focused on a specific compound, benzo[a]pyrene (B[a]P). $\mathrm{B}[\mathrm{a}] \mathrm{P}$ has been used as a model for PAH metabolism and cancer studies. Briefly, ingested PAHs can ultimately be converted to carcinogenic PAH-diol epoxides via metabolic enzymes [12]. These PAH-diol epoxides can bind DNA and create DNA adducts that interfere with gene transcription and confer genotoxic, mutagenic, and carcinogenic risk [10].

Table 1. IARC groups of polycyclic aromatic hydrocarbons are investigated in this study. Group 1: carcinogenic; group 2A: probably carcinogenic; group 2B: possibly carcinogenic; group 3: not classifiable; N/A: no information available.

\begin{tabular}{cc}
\hline Polycyclic Aromatic Hydrocarbon & IARC Group \\
\hline Acenaphthylene & $\mathrm{N} / \mathrm{A}$ \\
Anthracene & 3 \\
Benz[a]anthracene & $2 \mathrm{~B}$ \\
Benzo[a]pyrene & 1 \\
Benzo[b]fluoranthene & $2 \mathrm{~B}$ \\
Benzo[ghi]perylene & 3 \\
Benzo[k]fluoranthene & $2 \mathrm{~B}$ \\
Chrysene & $2 \mathrm{~B}$ \\
Dibenz[a,h]anthracene & $2 \mathrm{~A}$ \\
Fluorene & 3 \\
Indeno[1,2,3-cd]pyrene & $2 \mathrm{~B}$ \\
Phenanthrene & 3 \\
Pyrene & 3 \\
\hline
\end{tabular}

The consumption of red and processed meats is linked to colorectal, lung, oesophageal, gastric, and bladder malignancies [13], although it is unclear the exact role of PAHs in these associations. PAHs consumed via ingestion of meat have been primarily linked to cancers of the gastrointestinal tract [14], whilst exposure to environmental PAHs such as tobacco smoking, wood burning, and road traffic have primarily been linked to lung [12] and breast cancers [15]. There are limited studies investigating genetic effects of PAHs in colorectal cancer cells and tissues, however, current available literature investigates the effects of genetic variations i.e., polymorphisms and their risk on CRC [16-18]. Current epidemiological data suggests $\mathrm{B}[\mathrm{a}] \mathrm{P}$ (a surrogate $\mathrm{PAH}$ ) is associated with higher risk of CRC [19-21]. Furthermore, the presence of PAH-induced DNA adducts has been shown in the colon [22,23]. Given this evidence for a carcinogenic role of PAHs in CRC, there is limited information regarding PAHs and their potential effects on key genes involved in CRC, such as TP53, APC, CTNNB1, and KRAS [24]. Thus, our study aims to use a QuEChERS (quick, easy, cheap, effective, rugged, and safe) approach [25] to extract PAHs from processed meats in Australia to measure their occurrence in these and evaluate their in vitro effects on genes related to colorectal cancer.

\section{Results}

\subsection{PAH Detection via GC-MS}

Using the equipment and conditions described in Section 4.4, all $13 \mathrm{PAHs}$ were successfully detected via GC-MS. Figure S1 shows the chromatograms produced for each PAH that validates the parameters used in MS/MS. Using five identification points (10, 25, 50,100 , and $200 \mathrm{ppb}$ ) per PAH [26], calibrations curves were constructed and detailed in Table 2. As all $r$-values of regression were greater than 0.993 , these curve equations were deemed appropriate to use as calibration curves. 
Table 2. Equation characteristics for PAH quantification. Curve equations were determined using five points of identification $(10,25,50,100$, and $200 \mathrm{ppb})$. All curve equations had an $r$-value greater than 0.993 .

\begin{tabular}{ccccc}
\hline Standards & Mass (g) & $\begin{array}{c}\text { Concentration } \\
\text { Range }(\mathbf{p p b})\end{array}$ & Curve Equation & $\begin{array}{c}\text { Regression } \\
\text { Coefficient }\end{array}$ \\
\hline Acenaphthylene & $152.00>150.10$ & $10-200$ & $f(x)=0.2210 x^{2}+45.5552 x+0.0000$ & 0.9977 \\
Fluorene & $165.00>163.10$ & $10-200$ & $f(x)=0.3354 x^{2}+49.7426 x+0.0000$ & 0.9971 \\
Phenanthrene & $178.00>152.10$ & $10-200$ & $f(x)=0.4970 x^{2}+89.7263 x+0.0000$ & 0.9948 \\
Anthracene & $178.00>176.10$ & $10-200$ & $f(x)=0.4223 x^{2}+74.9640 x+0.0000$ & 0.9967 \\
Pyrene & $202.00>200.10$ & $10-200$ & $f(x)=0.3417 x^{2}+50.8238 x+0.0000$ & 0.9933 \\
Benzo[a]anthracene & $228.00>226.10$ & $10-200$ & $f(x)=0.4917 x^{2}+83.1846 x+0.0000$ & 0.9977 \\
Chrysene & $228.00>226.00$ & $10-200$ & $f(x)=0.6500 x^{2}+85.4511 x+0.0000$ & 0.9960 \\
Benzo[b]fluoranthene & $252.00>250.00$ & $10-200$ & $f(x)=0.2843 x^{2}+35.2259 x+0.0000$ & 0.9961 \\
Benzo[k]fluoranthene & $252.00>250.10$ & $10-200$ & $f(x)=0.4565 x^{2}+61.2200 x+0.0000$ & 0.9963 \\
Benzo[a]pyrene & $252.00>250.10$ & $10-200$ & $f(x)=0.3910 x^{2}+39.8408 x+0.0000$ & 0.9945 \\
Indeno[1,2,3- & $276.00>274.00$ & $10-200$ & $f(x)=0.2577 x^{2}+14.8013 x+0.0000$ & 0.9932 \\
cd]pyrene & $278.00>276.10$ & $10-200$ & $f(x)=0.4289 x^{2}+30.2481 x+0.0000$ & 0.9961 \\
Dibenz[a,h]anthracene & $276.00>274.00$ & $10-200$ & $f(x)=0.2677 x^{2}+23.2594 x+0.0000$ & 0.9951 \\
Benzo[ghi]perylene & & & & \\
\hline
\end{tabular}

\subsection{Recovery of PAHs Using QuEChERS Extraction}

PAHs were spiked at $1000 \mathrm{ng}$ into $6 \mathrm{~mL}$ of ACN. The extraction and detection then proceeded accordingly with blank and meat samples. Levels of $\mathrm{B}[\mathrm{b}] \mathrm{F}$ and $\mathrm{D}[\mathrm{a}, \mathrm{h}] \mathrm{A}$, which were detected by GC-MS, are detailed in Table 3. These levels were compared to the unspiked hexane blank, which did not contain detectable levels of these PAHs. B[b]F showed the highest level of recovery at $94 \%$ and $\mathrm{D}[\mathrm{a}, \mathrm{h}] \mathrm{A}$ was recovered at $74.5 \%$. These recovery values are acceptable and validate the QuEChERS method of PAH extraction in our meat samples.

Table 3. Recovery of PAHs as determined comparing spiked blanks and unspiked blanks.

\begin{tabular}{ccccc}
\hline PAH & $\begin{array}{c}\text { Spiked Concentration } \\
\text { ppb }\end{array}$ & $\begin{array}{c}\text { Mean Concentration } \\
\text { Detected ppb }\end{array}$ & $\begin{array}{c}\text { Unspiked Blank } \\
\text { Concentration ppb }\end{array}$ & Mean Recovery \% \\
\hline Benzo[b]fluoranthene & 1000 & 943.5 & 0 & 94.4 \\
Dibenz[a,h]anthracene & 1000 & 744.5 & 0 & 74.5 \\
\hline
\end{tabular}

\subsection{PAHs Are Found in Supermarket Meat Samples at Detectable Concentrations}

By using QuEChERS method of extraction and clean-up coupled with GC-MS analysis, we detected a variety of PAHs present in common supermarket ready-to-eat meat samples. GC-MS analysis found 9 of 13 PAH analytes present at detectable concentrations in meat samples as detailed in Table S1. The total concentration of polycyclic aromatic hydrocarbons in these meat samples ranged from $24.04 \mu \mathrm{g} / \mathrm{kg}$ to $90.75 \mu \mathrm{g} / \mathrm{kg}$. Meat samples in order of increasing PAH concentrations are: single smoked ham, roast chicken, frankfurt, double smoked ham, roast beef, triple smoked ham, salami, and roast turkey (Figure 1). The most abundant PAHs detected across all meat samples were phenanthrene and anthracene. Acenapthylene and chrysene were present only in salami and doublesmoked ham, respectively. Fluorene was detected at low levels in most samples except in single-smoked ham and salami, where it was absent and at high levels, respectively. Single-smoked ham contained the lowest total PAH, which was composed only of PHEN and ANTH. Interestingly, B[b]F and B[k]F were highly present in roast turkey. On the other hand, benzo[a]anthracene, indeno[1,2,3-cd]pyrene, dibenzo[a,h]anthracene, and benzo[ghi]perylene were not detected in any meat samples. 
Sum of PAH

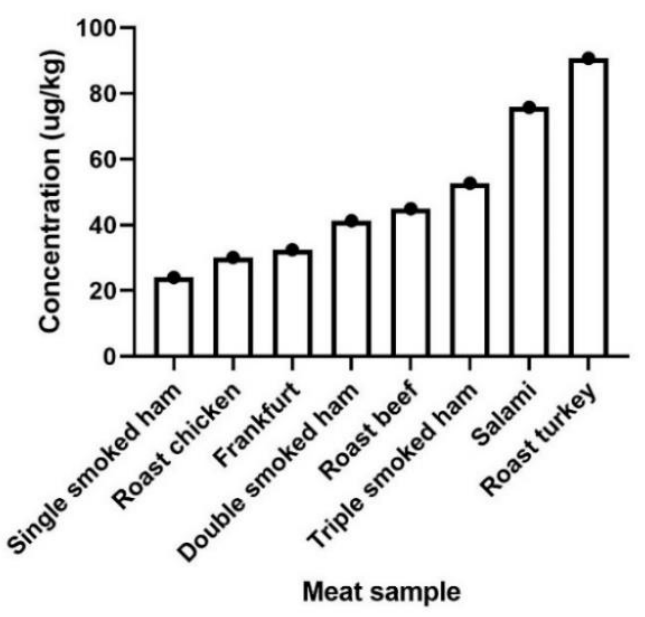

(a)
PAH concentrations in ham of different smoking levels

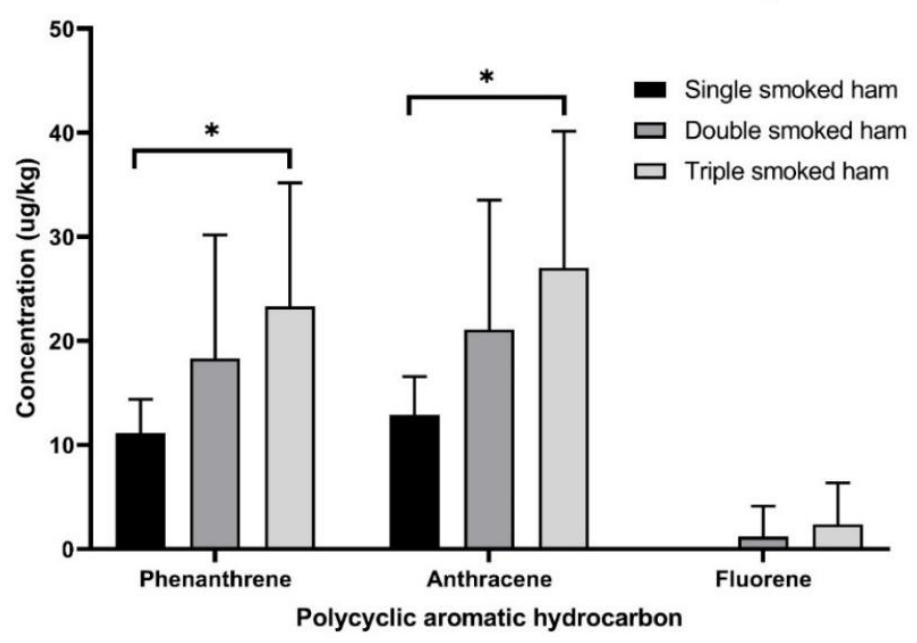

(b)

Figure 1. Graph (a) shows the total PAH levels detected in each meat sample of single-smoked ham containing the least PAH content and roast turkey having the highest total PAH while; (b) specifically shows that triple-smoked ham has significantly higher concentrations of phenanthrene and anthracene than single-smoked ham. ${ }^{*}=p<0.05$.

\subsection{Effect of Smoking in Ham on PAH}

To investigate the effect of smoking on PAH levels, three types of ready-to-eat ham samples were tested: single-, double-, and triple-smoked hams. As most nitrate-containing cured hams will undergo at least one round of smoking, we could not obtain a non-smoked ham sample for comparison. Noticeably, concentrations of two PAHs, phenanthrene and anthracene, increased as the level of smoking in ham increased. Furthermore, triple-smoked ham contains significantly higher [PHEN] $(p=0.035)$ and [ANTH] $(p=0.030)$ compared to its single-smoked counterpart (Figure 1). This shows a proportional relationship between PHEN and ANTH concentrations in meat with regards to level of smoking. This relationship is noted for fluorene, however, this was not statistically significant. This suggests that increased smoking during ham processing increases the formation of PHEN, ANTH, and to some extent FLU in ham samples.

\subsection{PAH Induced Genetic Changes In Vitro}

Low-dose B[a]P treatment significantly decreased TP53 expression in non-neoplastic colon cells (Figure 2). This decrease was statistically significant when compared to no template control (NTC) $(p=0.039)$ and vehicle control (VC) $(p=0.025)$ treatment groups. Notably, B[a]P at higher concentrations increased KRAS expression (in particular at $25 \mu \mathrm{M}$ and $10 \mu \mathrm{M})$ and was significantly increased from both NTC $(25 \mu \mathrm{M} p=0.003,10 \mu \mathrm{M}$ $p=0.000)$ and VC groups ( $25 \mu \mathrm{M} p=0.015,10 \mu \mathrm{M} p=0.005)$. Neither APC nor CTNNB1 expression were altered by $\mathrm{B}[\mathrm{a}] \mathrm{P}$ treatment.

Phenanthrene induced some changes in TP53, APC, and CTNNB1 expression when compared to the non-treated control group, however, this effect was not significant when compared to the vehicle control group. One micromolar of PHEN treatment significantly increased KRAS expression compared to control groups (NTC $p=0.005$; VC $p=0.03$ ).

Fluorene appeared to decrease TP53 expression across all treatment groups, however, this relationship was not significant when compared to both control groups. Similar to B[a]P, treatments with fluorene also increased KRAS expression. $25 \mu \mathrm{M}$ and $10 \mu \mathrm{M}$ treatment groups showed increased KRAS expression when compared to control groups: NTC (25 $\mu \mathrm{M}$ $p=0.003,10 \mu \mathrm{M} p=0.004)$ and $\mathrm{VC}(25 \mu \mathrm{M} p=0.016,10 \mu \mathrm{M} p=0.024)$. FLU treatments did not alter APC nor CTNNB1 expression. 


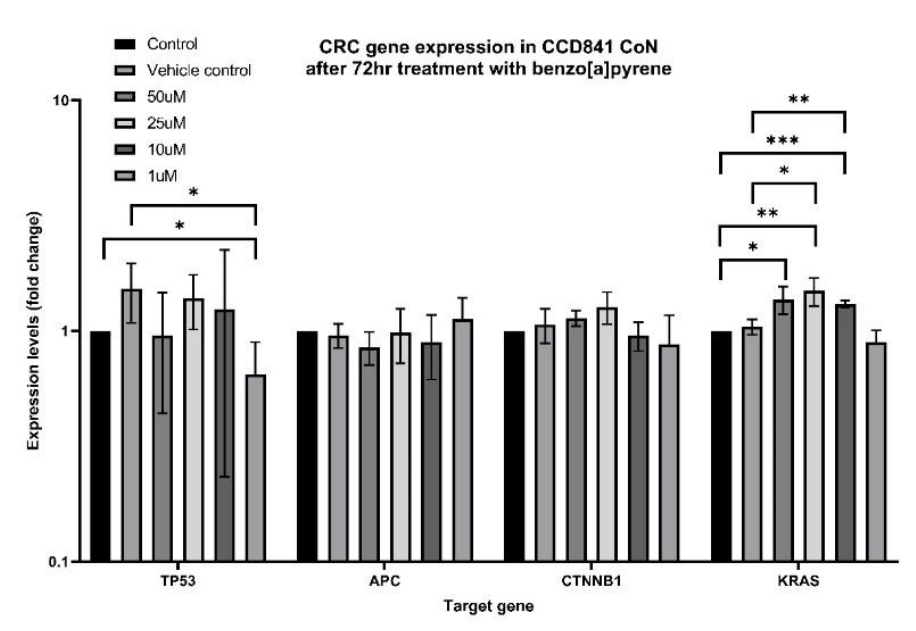

(a)

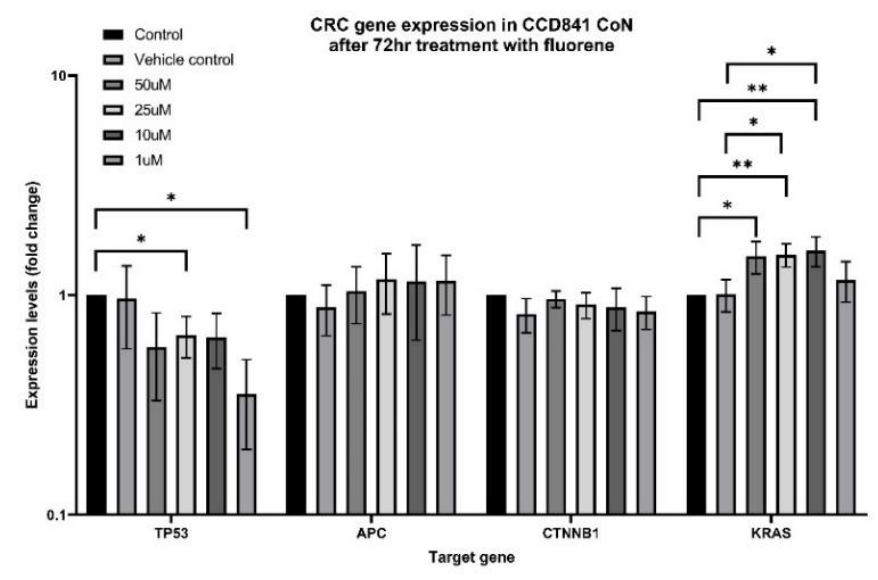

(c)

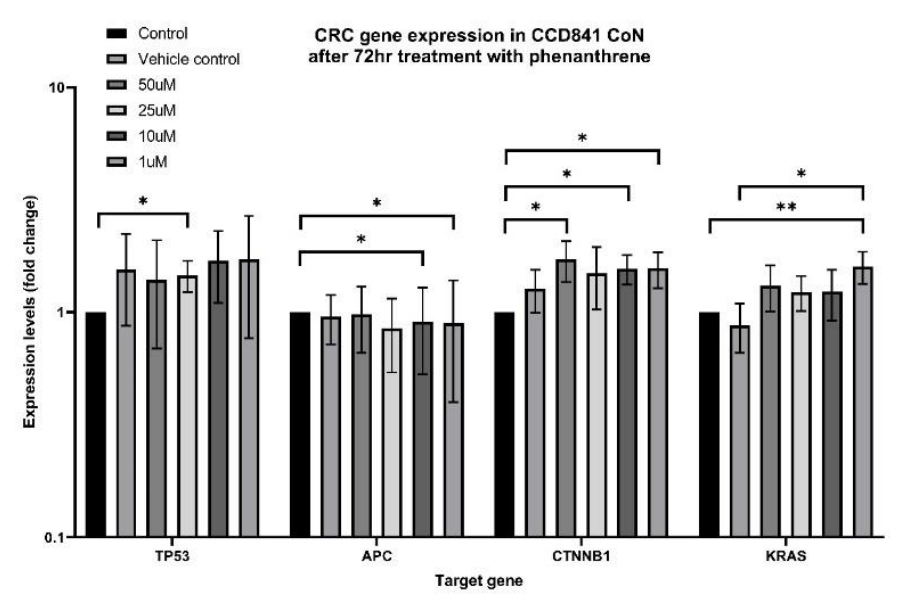

(b)

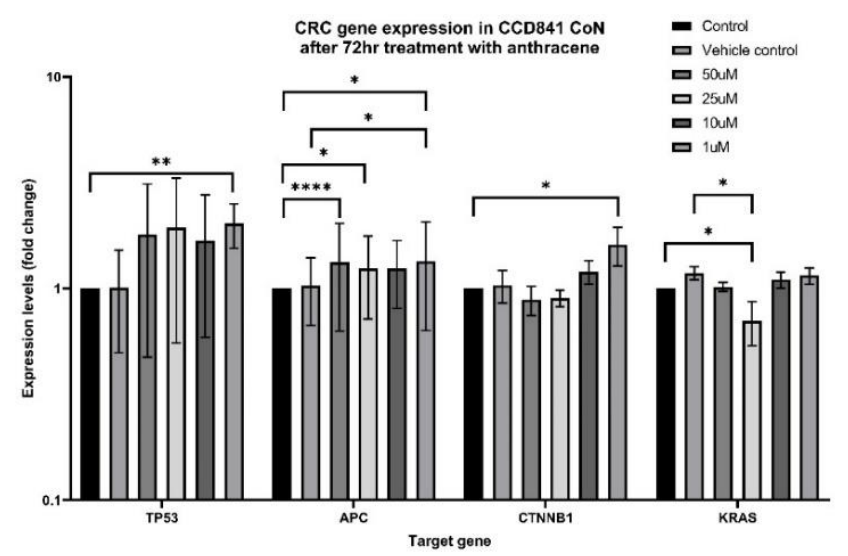

(d)

Figure 2. mRNA expression changes of TP53, APC, CTNNB1, and KRAS in CCD841 CoN cell line after 72-h treatment with (a) B[a]P; (b) PHEN; (c) FLU; and (d) ANTH. Statistical significance was considered at $p>0.05 .{ }^{*}=p<0.05$; ${ }^{* *}=p<0.01$; ${ }^{* * *}=p<0.001 ;{ }^{* * * *}=p<0.0001$.

One micromolar anthracene treatment significantly increased APC expression when compared to both the NTC group $(p=0.025)$ and the VC group $(p=0.012)$. Furthermore, $25 \mu \mathrm{M}$ of ANTH treatment significantly decreased KRAS expression compared to NTC $(p=0.04)$ and VC $(p=0.016)$. Effects of ANTH on TP53 and CTNNB1 were not statistically significant.

\section{Discussion}

The current study shows the presence of potentially carcinogenic polycyclic aromatic hydrocarbons in ready-to-eat cold cut samples obtained from a local supermarket and their ability to induce genetic changes in colon cancers in vitro. Detection of PAHs in meat samples in this study using QuEChERS and GC-MS complement those of Al-Thaiban et al.'s work, which used QuEChERS (Z-sep) to prepare samples of smoked meat from Qatar and successfully analysed 16 common PAHs [25]. Our results detected 9 of 13 PAHs analysed to be present in common ready-to-eat cold cuts of meat purchased from a supermarket in Queensland, Australia. The occurrence of these PAHs suggests that contamination of pre-prepared meat products is a source of PAH exposure in the gastrointestinal tract and provides a rationale for the red/processed meat hypothesis of colorectal carcinogenesis.

Our results showed PHEN and ANTH were present in higher levels in ham that had undergone more rounds of smoking. This is consistent with the literature that PHEN and ANTH are considered more abundant PAHs [27] and smoking of food increases PAH 
formation. $\mathrm{B}[\mathrm{a}] \mathrm{P}$ was detected in roast beef, roast chicken, and frankfurt samples, which corroborates well with a PAH database developed by Jakszyn et al. [28]. We hypothesise that $\mathrm{I}[1,2,3-\mathrm{cd}] \mathrm{P}, \mathrm{D}[\mathrm{a}, \mathrm{h}] \mathrm{A}$, and $\mathrm{B}[\mathrm{ghi}] \mathrm{P}$ were absent from meat samples due to their high molecular weight and more extensive ring structure being less likely to be formed during incomplete combustion reactions. Jakszyn et al.' s database seldom detected $\mathrm{D}[\mathrm{a}, \mathrm{h}] \mathrm{A}$ in meat and meat products, and when present were at very low amounts [28]. Furthermore, we detected similar PAHs across ham samples, but differentiated PAHs across all samples. We hypothesise that different animal sources could yield different PAHs during the cooking process, and factors such as fat content and other ingredients used during meat preparation were not controlled for in this current study. Available literature is inconclusive regarding different meat types and PAH formation $[29,30]$.

Overall, roasted turkey contained the highest total PAHs, and this may be attributed to the pattern of fat distribution throughout the meat. Roast turkey samples contained regions of pure fat, which were not observed as obviously in other meat samples. Areas of high fat concentration that are subject to high temperatures during the roasting process are more likely to create fat drippings. Fat drippings onto the source of heat undergo incomplete combustion and are a significant contributor to smoke and PAHs formation [31]. High levels of PAHs in roast turkey were in contrast to the findings in the roast chicken sample, which only contained approximately one-third of the amount of total PAHs. This is congruent with the fat-drippings rationale as the chicken meat sample did not contain any regions of pure fat whilst the turkey sample used contained a layer of fat around the meat.

As nine different PAHs were detectable in meat samples, we chose B[a]P, PHEN, FLU, and ANTH to further investigate effects on four genes associated with colorectal cancer: TP53, APC, CTNNB1, and KRAS [24]. Varying concentrations of these PAHs were utilised as treatments for 72-h treatments as an estimate of maximal food transit time. These results showed that these PAHs that were detected in meat samples can exert genetic changes in a cell model of non-neoplastic epithelial colon cells.

$\mathrm{B}[\mathrm{a}] \mathrm{P}$ did not show any effect on APC or CTNNB1 expression in CCD841 CoN cells. Thus, its carcinogenic effects are unlikely to be via genetic changes to the APC/Wnt/ $\beta$-cat pathway. However, this result is limited to one human cell line model of colon epithelial cells. There is evidence that $\mathrm{B}[\mathrm{a}] \mathrm{P}$ down-regulates $C T N N B 1$ and $A P C$ expression in the colon and stomach cells in mice [32], and the relationship between the APC/Wnt/b-cat pathway and PAHs in humans requires further investigation. We showed $\mathrm{B}[\mathrm{a}] \mathrm{P}$ was capable of increasing KRAS expression at higher doses $(25 \mu \mathrm{M}$ and $10 \mu \mathrm{M})$ and decreasing p53 mRNA expression at lower doses $(1 \mu \mathrm{M})$. Upregulation of proto-oncogene $K R A S$ is a significant finding, however, it is unlikely human ingestion of $\mathrm{B}[\mathrm{a}] \mathrm{P}$ is comparable to $25-10 \mu \mathrm{M}$ treatment concentration. Of more clinical importance, a lower dose of $\mathrm{B}[\mathrm{a}] \mathrm{P}(1 \mu \mathrm{M})$ significantly downregulates TP53 expression and suggests a mechanism for colorectal carcinogenesis via consumption of B[a]P-contaminated meat. Decreased p53 lowers the tumour-suppressive capability of a cell and leads to cell cycle dysregulation and uncontrolled cell growth [33]. $\mathrm{B}[\mathrm{a}] \mathrm{P}$ is capable of inducing p53 mutations in lung cancers [34] and corroborates well with our findings whereby mutated p53 is not able to be induced in response to cellular stressors. However, significant cell stress brought on by $\mathrm{B}[\mathrm{a}] \mathrm{P}$ treatment is able to transcriptionally induce p53 expression to some degree in human hepatoma cells [35] and in mouse cervical tissue [36]. Overall, B[a]P can create significant cell stress and induce TP53 expression for cell protection. However, our results indicated that low dose B[a]P can downregulate TP53, perhaps by inducing a mutation in vitro, which warrants further investigation into the link between $\mathrm{B}[\mathrm{a}] \mathrm{P}$ and colorectal carcinogenesis.

Low-dose PHEN after $72 \mathrm{~h}$ showed significantly increased KRAS expression in human non-neoplastic colon cells. KRAS encoding for k-ras protein is a molecular on/off switch controlling cell growth and differentiation [37]. Inappropriately high expression of kras protein is predominately associated with an activating mutation of the KRAS gene, thus converting it from a proto-oncogene to an oncogene. Thus, the high level of KRAS expression brought on by PHEN treatment may suggest a carcinogenic link between 
PHEN and CRC. Similarly, moderate doses of FLU $(25 \mu \mathrm{M}$ and $10 \mu \mathrm{M})$ showed a similar increase in KRAS expression. Neither PHEN nor FLU caused other genetic changes of CRC-related genes.

Treatment of CCD841 CoN with ANTH significantly decreased KRAS mRNA expression and increased APC expression. Although not statistically significant, ANTH also seemed to increase TP53 and CTNNB1 mRNA expression. Anthracene is a PAH that does not harbour a bay region and is thus theorised to be less carcinogenic compared to a bay region counterpart [38]. The bay region theory predicts that PAH-diol epoxides formed from an epoxide that is part of the bay region will have higher biological activity and thus be more mutagenic and/or tumorigenic [38]. Our results support the bay region carcinogenicity hypothesis as CCD841 CoN treated with ANTH exhibits anti-carcinogenic mRNA changes. The increased mRNA expression of APC after $1 \mu \mathrm{M}$ ANTH treatment allows the cell to negatively regulate the APC/Wnt/b-cat pathway. Although low dose ANTH induced CTNNB1, it also slightly increased APC, thus it would be unlikely to lead to any overall change in activity of beta-catenin-targeted gene transcription.

\section{Materials and Methods}

\subsection{Chemicals}

Thirteen polycyclic aromatic hydrocarbons were analysed in this study. Certified reference material EPA 525 PAH Mix B (SupelCo, Bellefonte, PA, USA) was acquired as an internal standard, containing: acenaphthylene (ACNY), anthracene (ANTH), benz[a]anthracene $(\mathrm{B}[\mathrm{a}] \mathrm{A})$, benzo[b]fluoranthene $(\mathrm{B}[\mathrm{b}] \mathrm{F})$, benzo[k]fluoranthene $(\mathrm{B}[\mathrm{k}] \mathrm{F})$, benzo[ghi]perylene (B[ghi]P), benzo[a]pyrene $(\mathrm{B}[\mathrm{a}] \mathrm{P})$, chrysene $(\mathrm{CHRY})$, dibenz[a,h]anthracene $(\mathrm{D}[\mathrm{ah}] \mathrm{A})$, fluorene (FL), indeno[1,2,3-cd]pyrene (I[123-cd]P), phenanthrene (PHEN), and pyrene (PYR).

Sodium chloride $(\mathrm{NaCl})$, magnesium sulfate $\left(\mathrm{MgSO}_{4}\right)$, and hexane $\left(\mathrm{C}_{6} \mathrm{H}_{14}\right)(\mathrm{HPLC}$ grade) were obtained from Sigma-Aldrich (St. Louis, MO, USA). Hypergrade acetonitrile (ACN) was purchased from Merck (Kenilworth, NJ, USA). Sample clean-up was performed using Supel QuE Z-Sep tubes (SupelCo). Preparation of samples was performed using polypropylene tubes. Glass tubes were used during extraction to minimise interference of the samples.

\subsection{Meat Samples}

Meat samples of eight varying animal origins or preparation methods were acquired from a local supermarket delicatessen (Gold Coast, Queensland, Australia) as detailed in Table 4. Triplicates were acquired at least 2 weeks apart to ensure samples originated from different sources (knobs of ham, cuts of beef, etc.). Each sample was processed as a technical duplicate with $2 \mathrm{~g}$ of each sample per replicate.

Table 4. Details of meat samples obtained from a local supermarket, including procedures of meat cooking/preparation.

\begin{tabular}{cccc}
\hline Sample Name & Meat & Preparation Method & $\begin{array}{c}\text { Number of Replicates } \\
\text { (Technical; Biological) }\end{array}$ \\
\hline Roast turkey & Turkey & Roasted & $2 ; 3$ \\
Roast beef & Beef & Roasted & $2 ; 3$ \\
Roast chicken & Chicken & Roasted & $2 ; 3$ \\
Frankfurt & Pork & Smoked meat trimmings & $2 ; 3$ \\
Single smoked ham & Pork & Single smoked & $2 ; 3$ \\
Double smoked ham & Pork & Double smoked & $2 ; 3$ \\
Triple smoked ham & Pork & Triple smoked & $2 ; 3$ \\
Salami & & Fermented and matured with smoke & $2 ; 3$ \\
\hline
\end{tabular}

\subsection{Extraction and Clean-Up}

Extraction of PAHs was performed using a type of solid phase extraction, QuEChERS (quick, easy, cheap, effective, rugged, and safe) method based on Al-Thaiban's study [25], and summarised in Figure S2. Briefly, the homogenised samples (in $6 \mathrm{~mL}$ deionised 
water) were thoroughly mixed with $6 \mathrm{~mL} \mathrm{ACN}$ and kept overnight at $4{ }^{\circ} \mathrm{C}$. Five hundred milligrams of $\mathrm{NaCl}$ and $3 \mathrm{~g} \mathrm{MgSO}_{4}$ were added to each sample and mixed thoroughly for $1 \mathrm{~min}$. These samples were then centrifuged, and the supernatant was transferred to a QuE Z-sep tube. This was thoroughly mixed prior to further centrifugation. Once again, the supernatant was extracted, being careful to avoid the clean-up crystals in the Z-sep tubes. Samples were evaporated to dryness, reconstituted in $200 \mu \mathrm{L}$ hexane, and stored at $-20^{\circ} \mathrm{C}$.

\subsection{GC-MS Equipment and Conditions}

Gas chromatography-mass spectrometry was performed on the GCMS-TQ8030 triple quadrupole gas chromatograph (Shimadzu, Kyoto, Japan). Gas separation was performed on a $30 \mathrm{~m}$ Rxi-5 ms column of $0.25 \mathrm{~mm}$ inner diameter and $0.25 \mu \mathrm{m}$ thickness (Restek, Bellefonte, PA, USA). Helium was the carrier gas at a pressure of $92.8 \mathrm{kPa}$. A $10 \mu \mathrm{L}$ syringe for liquid injection was used to inject the sample via split mode (ratio 5.0 ) at $270{ }^{\circ} \mathrm{C}$. The initial oven temperature was $120^{\circ} \mathrm{C}$, which was increased to $270{ }^{\circ} \mathrm{C}$ over $25 \mathrm{~min}$ and held for $3 \mathrm{~min}$. Mass spectrometric parameters were set at $230^{\circ} \mathrm{C}$ as the ion source temperature, an interface temperature of $200^{\circ} \mathrm{C}$, and a solvent cut time of $2.5 \mathrm{~min}$.

\subsection{Recovery Study}

Recovery experiments were conducted for D[ah]A and B[b]F by spiking $1 \mu \mathrm{g}$ of each into ACN at the beginning of the extraction protocol. These spiked samples were subject to the entire extraction and detection methodology across three independent experiments, each with two technical replicates. Quantification of recovery was calculated by comparing spiked and unspiked blanks.

\subsection{Quantification of PAHs}

Thirteen PAHs via EPA mix B were subjected to GC/MS as per the conditions above. Calibration curves were constructed using concentrations of 10, 25, 50, 100, and $200 \mathrm{ppb}$ (xaxis) against the corresponding height (y-axis). The threshold for acceptance of a calibration curve was a correlation coefficient $\left(\mathrm{R}^{2}\right)$ greater than 0.97 . Quantification of PAH from meat sample extracts was achieved by plotting height values of samples on the calibration curve corresponding to the matched PAH analyte.

\subsection{Cell Culture}

An in vitro model of non-neoplastic epithelial-like colon cells was created by recruiting the CCD841 CoN cell line from (ATCC CRL-1790). Cells were cultured following American Type Culture Collection (ATCC) guidelines. CCD841 CoN was cultured in EMEM (Eagle's Minimum Essential Medium) supplemented with 10\% fetal bovine serum (FBS). Cells were incubated at $37^{\circ} \mathrm{C}$ with $5 \% \mathrm{CO}_{2}$.

\subsection{PAH Treatment}

CCD841 CoN cells were seeded in six-well plates for $24 \mathrm{~h}$ prior to treatment with PAHs. Benzo[a]pyrene, phenanthrene, fluorene, and anthracene were purchased from Sigma-Aldrich and prepared as $50 \mathrm{mM}$ stock solutions in dimethylsulfoxide (DMSO) and stored away from the light at $4{ }^{\circ} \mathrm{C}$. PAH stock solutions $(50 \mathrm{mM})$ were transferred to a dosing plate with final concentrations of $50 \mu \mathrm{M}, 25 \mu \mathrm{M}, 10 \mu \mathrm{M}$, and $1 \mu \mathrm{M}$ diluted in EMEM $+10 \%$ fetal bovine serum (FBS) media and used to treat six-well plates. Non-treated control (NTC) treatments involved EMEM $+10 \%$ FBS media in place of PAH treatment, and vehicle control (VC) treatment consisted of treating cells with $0.2 \%$ DMSO in place of PAH. Cells were incubated for $72 \mathrm{~h}$ prior to downstream experiments.

\subsection{RNA Extraction and Quantitative Real-Time Polymerase Chain Reaction (rtPCR)}

CCD841 CoN ${ }^{+\mathrm{PAH}}$ cells were harvested via trypsinisation and RNA was extracted using miRNeasy mini kit (Qiagen, Valencia, CA, USA) following the manufacturer's protocol. Total RNA purity and quantification was performed using Nanodrop Spectrophotometer, 
measured via $260 / 280$ and $\mathrm{ng} / \mu \mathrm{L}$, respectively. This RNA was converted to cDNA using SensiFAST cDNA synthesis kit (Meridian Bioscience, Cincinnati, OH, USA) following the manufacturer's guidelines. cDNA was again measured using a Nanodrop spectrophotometer (BioLab, Milford, MA, USA) and diluted to a $100 \mathrm{ng} / \mu \mathrm{L}$ working concentration. The mRNA expressions of TP53, APC, CTNNB1, and KRAS were investigated using rtPCR (QuantStudio, Thermostat Fisher Scientific, Waltham, MA, USA). Glyceraldehyde-3-phosphate dehydrogenase (GAPDH) was used as a housekeeping gene. Primer sequences are detailed in Table S2.

\subsection{Statistical Analysis}

Analyses with PAH concentrations in meat samples were performed in GraphPad Prism 9.0 (San Diego, CA, USA) using unpaired $t$-tests. rtPCR analysis was performed as previously reported [39]. Statistical analysis of gene expression study was performed by comparing the difference in $C_{t}$ values but presented graphically as fold changes. Statistical significance level was considered at $p<0.05$.

\section{Conclusions}

This study demonstrated a link between PAH compounds in processed meat and alteration of colorectal cancer genes. Our study validated the use of QuEChERS method for PAH sample preparation from meat sources, which allows for quick, easy, and cheap extraction and clean-up for future studies. Using this method, we showed that commonly consumed ready-to-eat meat samples, which did not undergo any further processing or cooking, contain various polycyclic aromatic hydrocarbons. Congruent with the available literature, phenanthrene, anthracene, and fluorene were most detected among meat samples. Furthermore, benzo[a]pyrene was present in three of the eight meat samples investigated. The four PAHs showed capabilities of colorectal cancer-related gene alterations in a non-neoplastic human colon cell line. This study may provide direction for future investigations regarding processing of meat and the mechanisms by which red and processed meat intake might confer colorectal cancer risk.

Supplementary Materials: The following are available online at https://www.mdpi.com/article/10 .3390/ijms222010959/s1.

Author Contributions: Conceptualization, T.C., S.C. and V.G.; methodology, T.C. and S.C.; software, T.C.; validation, T.C., S.C., V.G. and A.K.-y.L.; formal analysis, T.C.; investigation, T.C., S.C. and S.M.K.G.; V.G. and A.K.-y.L.; data curation, T.C., S.C. and S.M.K.G.; writing-original draft preparation, T.C.; writing-review and editing, T.C., S.C., S.M.K.G., V.G. and A.K.-y.L.; visualization, T.C.; supervision, V.G. and A.K.-y.L.; project administration, V.G.; funding acquisition, V.G. and A.K.-y.L. All authors have read and agreed to the published version of the manuscript.

Funding: This research received no external funding.

Institutional Review Board Statement: Not applicable.

Informed Consent Statement: Not applicable.

Data Availability Statement: The data presented in this study are available in Polycyclic Aromatic Hydrocarbons Detected in Processed Meats Cause Genetic Changes in Colorectal Cancers and its supplementary material within.

Acknowledgments: Alan White and Tanora Pouniu for their technical assistance. Some figures were created using BioRender.com under a paid subscription.

Conflicts of Interest: The authors declare no conflict of interest. 


\section{References}

1. Rawla, P.; Sunkara, T.; Barsouk, A. Epidemiology of colorectal cancer: Incidence, mortality, survival, and risk factors. Prz. Gastroenterol. 2019, 14, 89-103. [CrossRef]

2. Parkin, D.M.; Boyd, L.; Walker, L.C. 16. The fraction of cancer attributable to lifestyle and environmental factors in the UK in 2010. Br. J. Cancer 2011, 105, S77-S81. [CrossRef]

3. Watson, A.J.M.; Collins, P.D. Colon cancer: A civilization disorder. Dig. Dis. 2011, 29, 222-228. [CrossRef]

4. Hamidi, E.N.; Hajeb, P.; Selamat, J.; Razis, A.F.A. polycyclic aromatic hydrocarbons (pahs) and their bioaccessibility in meat: A tool for assessing human cancer risk. Asian Pac. J. Cancer Prev. 2016, 17, 15-23. [CrossRef]

5. Bouvard, V.; Loomis, D.; Guyton, K.Z.; Grosse, Y.; Ghissassi, F.E.; Benbrahim-Tallaa, L.; Guha, N.; Mattock, H.; Straif, K. International Agency for Research on Cancer Monograph working group carcinogenicity of consumption of red and processed meat. Lancet Oncol. 2015, 16, 1599-1600. [CrossRef]

6. Zelinkova, Z.; Wenzl, T. The Occurrence of 16 EPA PAHs in Food-A Review. Polycycl. Aromat. Compd. 2015, 35, 248-284. [CrossRef]

7. Duedahl-Olesen, L.; Ionas, A.C. Formation and mitigation of pahs in barbecued meat-A review. Crit. Rev. Food Sci. Nutr. 2021, 1-16. [CrossRef] [PubMed]

8. Phillips, D.H. Polycyclic Aromatic Hydrocarbons in the Diet. Mutat. Res. Genet. Toxicol. Environ. Mutagenes. 1999, $443,139-147$. [CrossRef]

9. Australian Health Survey: Nutrition First Results-Foods and Nutrients, 2011-2012 Financial Year I Australian Bureau of Statistics. Available online: https://www.abs.gov.au/statistics/health/health-conditions-and-risks/australian-health-survey-nutritionfirst-results-foods-and-nutrients / latest-release (accessed on 19 August 2021).

10. Abdel-Shafy, H.I.; Mansour, M.S.M. A review on polycyclic aromatic hydrocarbons: Source, environmental impact, effect on human health and remediation. Egypt. J. Pet. 2016, 25, 107-123. [CrossRef]

11. IARC Working Group on the Evaluation of Carcinogenic Risks to Humans. Some Non-Heterocyclic Polycyclic aromatic hydrocarbons and some related exposures. IARC Monogr. Eval. Carcinog. Risks Hum. 2010, 92, 1-853.

12. Moorthy, B.; Chu, C.; Carlin, D.J. Polycyclic aromatic hydrocarbons: From metabolism to lung cancer. Toxicol. Sci. 2015, 145, 5-15. [CrossRef] [PubMed]

13. Lippi, G.; Mattiuzzi, C.; Cervellin, G. Meat consumption and cancer risk: A critical review of published meta-analyses. Crit. Rev. Oncol. Hematol. 2016, 97, 1-14. [CrossRef]

14. Diggs, D.L.; Huderson, A.C.; Harris, K.L.; Myers, J.N.; Banks, L.D.; Rekhadevi, P.V.; Niaz, M.S.; Ramesh, A. Polycyclic aromatic hydrocarbons and digestive tract cancers-A perspective. J. Environ. Sci. Health C Environ. Carcinog. Ecotoxicol. Rev. 2011, 29, 324-357. [CrossRef] [PubMed]

15. Korsh, J.; Shen, A.; Aliano, K.; Davenport, T. Polycyclic aromatic hydrocarbons and breast cancer: A review of the literature. Breast Care 2015, 10, 316-318. [CrossRef] [PubMed]

16. Reszka, E.; Wasowicz, W.; Gromadzinska, J. Genetic polymorphism of xenobiotic metabolising enzymes, diet and cancer susceptibility. Br. J. Nutr. 2006, 96, 609-619.

17. Coles, B.F.; Kadlubar, F.F. Human Alpha Class Glutathione S-Transferases: Genetic Polymorphism, Expression, and Susceptibility to Disease. Methods Enzymol. 2005, 401, 9-42.

18. Chung, F.F.-L.; Mai, C.W.; Ng, P.Y.; Leong, C.-O. Cytochrome P450 2W1 (CYP2W1) in colorectal cancers. Curr. Cancer Drug Targets 2016, 16, 71-78. [CrossRef]

19. Sinha, R.; Peters, U.; Cross, A.J.; Kulldorff, M.; Weissfeld, J.L.; Pinsky, P.F.; Rothman, N.; Hayes, R.B. Meat, Meat cooking methods and preservation, and risk for colorectal adenoma. Cancer Res. 2005, 65, 8034-8041. [CrossRef]

20. Sinha, R.; Kulldorff, M.; Gunter, M.J.; Strickland, P.; Rothman, N. Dietary Benzo[a]Pyrene intake and risk of colorectal adenoma. Cancer Epidemiol. Biomark. Prev. 2005, 14, 2030-2034. [CrossRef] [PubMed]

21. Miller, P.E.; Lazarus, P.; Lesko, S.M.; Cross, A.J.; Sinha, R.; Laio, J.; Zhu, J.; Harper, G.; Muscat, J.E.; Hartman, T.J. Meat-related compounds and colorectal cancer risk by anatomical subsite. Nutr. Cancer 2013, 65, 202-226. [CrossRef]

22. Wohak, L.E.; Krais, A.M.; Kucab, J.E.; Stertmann, J.; Øvrebø, S.; Seidel, A.; Phillips, D.H.; Arlt, V.M. Carcinogenic polycyclic aromatic hydrocarbons induce cyp1a1 in human cells via a P53-dependent mechanism. Arch. Toxicol. 2016, 90, 291-304. [CrossRef]

23. Alexandrov, K.; Rojas, M.; Kadlubar, F.F.; Lang, N.P.; Bartsch, H. Evidence of anti-benzo[a]pyrene diolepoxide-dna adduct formation in human colon mucosa. Carcinogenesis 1996, 17, 2081-2083. [CrossRef] [PubMed]

24. Armaghany, T.; Wilson, J.D.; Chu, Q.; Mills, G. Genetic alterations in colorectal cancer. Gastrointest. Cancer Res. 2012,5 , $19-27$.

25. Al-Thaiban, H.; Al-Tamimi, N.; Helaleh, M. Development of QuEChERS Method for the Determination of Polycyclic Aromatic Hydrocarbons in Smoked Meat Products Using GC-MS from Qatar. Available online: https:/ /www.hindawi.com/journals / jamc/2018/9206237/ (accessed on 23 February 2021).

26. 2002/657/EC: Commission Decision of 12 August 2002 Implementing Council Directive 96/23/EC Concerning the Performance of Analytical Methods and the Interpretation of Results (Text with EEA Relevance) (Notified under Document Number C(2002) 3044). Available online: https:/ / op.europa.eu/en/publication-detail/-/publication/ed928116-a955-4a84-b10a-cf7a82bad858 /language-en (accessed on 10 September 2021).

27. García-Falcón, M.S.; Simal-Gándara, J. Polycyclic aromatic hydrocarbons in smoke from different woods and their transfer during traditional smoking into chorizo sausages with collagen and tripe casings. Food Addit. Contam. 2005, 22, 1-8. [CrossRef] [PubMed] 
28. Jakszyn, P.; Agudo, A.; Ibáñez, R.; García-Closas, R.; Pera, G.; Amiano, P.; González, C.A. Development of a food database of nitrosamines, heterocyclic amines, and polycyclic aromatic hydrocarbons. J. Nutr. 2004, 134, 2011-2014. [CrossRef]

29. Farhadian, A.; Jinap, S.; Abas, F.; Sakar, Z.I. Determination of polycyclic aromatic hydrocarbons in grilled meat. Food Control 2010, 21, 606-610. [CrossRef]

30. Babaoglu, A.S.; Karakaya, M.; Öz, F. Formation of polycyclic aromatic hydrocarbons in beef and lamb kokorec: Effects of different animal fats. Int. J. Food Prop. 2017, 20, 1960-1970. [CrossRef]

31. Lee, J.-G.; Kim, S.-Y.; Moon, J.-S.; Kim, S.-H.; Kang, D.-H.; Yoon, H.-J. Effects of grilling procedures on levels of polycyclic aromatic hydrocarbons in grilled meats. Food Chem. 2016, 199, 632-638. [CrossRef]

32. Zuo, J.; Brewer, D.S.; Arlt, V.M.; Cooper, C.S.; Phillips, D.H. Benzo Pyrene-Induced DNA adducts and gene expression profiles in target and non-target organs for carcinogenesis in mice. BMC Genom. 2014, 15, 880. [CrossRef] [PubMed]

33. National Center for Biotechnology Information (US). The P53 Tumor Suppressor Protein; National Center for Biotechnology Information (US): Bethesda, MI, USA, 1998.

34. Liu, Z.; Muehlbauer, K.-R.; Schmeiser, H.H.; Hergenhahn, M.; Belharazem, D.; Hollstein, M.C. P53 mutations in benzo(a)pyreneexposed human p53 knock-in murine fibroblasts correlate with p53 mutations in human lung tumors. Cancer Res. 2005, 65, 2583-2587. [CrossRef]

35. Park, S.-Y.; Lee, S.-M.; Ye, S.-K.; Yoon, S.-H.; Chung, M.-H.; Choi, J. Benzo[a]Pyrene-induced dna damage and p53 modulation in human hepatoma HepG2 cells for the identification of potential biomarkers for pah monitoring and risk assessment. Toxicol. Lett. 2006, 167, 27-33. [CrossRef] [PubMed]

36. Gao, M.; Li, Y.; Sun, Y.; Long, J.; Kong, Y.; Yang, S.; Wang, Y. A Common Carcinogen Benzo[a]Pyrene Causes P53 overexpression in mouse cervix via dna damage. Mutat. Res. Genet. Toxicol. Environ. Mutagenes. 2011, 724, 69-75. [CrossRef] [PubMed]

37. KRAS KRAS Proto-Oncogene, GTPase [Homo Sapiens (Human)]-Gene-NCBI. Available online: https:/ /www.ncbi.nlm.nih.gov / gene/3845 (accessed on 14 July 2021).

38. Jerina, D.M.; Sayer, J.M.; Thakker, D.R.; Yagi, H.; Levin, W.; Wood, A.W.; Conney, A.H. Carcinogenicity of polycyclic aromatic hydrocarbons: The bay-region theory. In Carcinogenesis: Fundamental Mechanisms and Environmental Effects; Pullman, B., Ts'o, P.O.P., Gelboin, H., Eds.; Springer: Dordrecht, The Netherlands, 1980; pp. 1-12.

39. Gamage, S.M.K.; Islam, F.; Cheng, T.; Aktar, S.; Lu, C.T.; Ranaweera, C.D.; Lee, K.T.W.; Dissabandara, L.; Gopalan, V.; Lam, A.K. HFE variants in colorectal cancer and their clinicopathological correlations. Hum. Pathol. 2021, 117, 9-30. [CrossRef] [PubMed] 